\title{
Colour vision in long-standing diabetes mellitus
}

\author{
M. S. ROY, C. McCUlloCH, A. K. HANNA, And C. MORTIMER \\ From the Department of Health and Human Services, National Institutes of Health, Bethesda, Maryland, USA
}

SUMMARY In 12 long-standing insulin-dependent diabetics with background diabetic retinopathy their 100 -hue colour vision scores were positively related to the degree of retinopathy and negatively to fasting blood glucose levels. However, the 100 -hue colour vision scores and types were not significantly different from those of normal subjects matched for age, sex, and social class.

A number of reports have appeared on blue-yellow and green-blue chromatic discrimination losses in patients with diabetes mellitus. ${ }^{1-5}$ This loss has been correlated with the presence of clinical diabetic retinopathy, ${ }^{12}$ the duration, ${ }^{1}$ and the metabolic control $^{5}$ of the diabetes. That the loss may precede the appearance of clinical diabetic retinopathy is suspected but not yet firmly established. With increasing age there is a gradual deterioration of blueyellow colour discrimination,,$^{6-8}$ and colour vision tests are not equally sensitive in detecting early defects. ${ }^{9}$

The aim of this study is to assess colour vision in long-standing diabetics with minimal background diabetic retinopathy when matched for age, sex, and social class with normal controls and to relate it to the quality of diabetic control.

\section{Patients and methods}

From July 1979 to June 1982 we examined a consecutive series of 22 insulin-dependent diabetics with fewer than 10 microaneurysms or microhaemorrhages at the posterior pole on fluorescein angiography and more than 25 years of diabetes. The patients were selected from those attending the ophthalmology and diabetic clinics at Toronto General Hospital. They were part of a separate study for which they were submitted to detailed ocular, systemic, and biological investigations. Ocular examination included a biomicroscopic examination of the retina, fundus photography (Diabetic Retinopathy Study 7 fields) and fluorescein angiography. Ten patients were subsequently excluded: 7 because of lens changes as assessed by slit-lamp biomicroscopy, 2 because of

Correspondence to Dr M. S. Roy, FRCS(C), National Eye Institute, Building 10, Room 10N313, NIH, Bethesda, Maryland 20816, USA. congenital colour defects, and 1 because of treated open-angle glaucoma.

Patients were given the Farnsworth 100-hue colour vision test as modified by Parker. ${ }^{10}$ All patients were tested after their lunch. Each eye, right eye first, left eye second, was examined separately under the standard conditions of illumination. The scoring method was as described by Parker. ${ }^{10}$ Assessment of the metabolic control of the diabetes included all previous fasting and postprandial glucose estimations obtained from the patient and his doctors and at the time of admission fasting and postprandial blood glucose (5 estimations per day for 5 days) and $\mathrm{Hb} \mathrm{A}_{1}$ C levels ( 3 estimations).

Although the diabetic patients were initially selected for having little retinopathy, there were differences in severity of retinopathy among the patients, and all these diabetics were noted to have peripheral retinal haemorrhages on careful biomicroscopic examination of the retina. ${ }^{11}$ It was therefore decided to grade the severity of retinopathy as mild $(\mathrm{m})$ when there were fewer than or equal to 5 microaneurysms or microhaemorrhages at the posterior pole and moderate (Mo) when there were more than 5 microaneurysms or microhaemorrhages at the posterior pole. Grading of the peripheral haemorrhages was + for less than or equal to 10 microhaemorrhages and ++ for more than 10 microhaemorrhages.

Because the presence of a few large numbers of 100-hue scores could distort the distribution, the logarithm of the colour vision score was used for this analysis, and the distribution of scores thus obtained was closer to normal after this transformation.

Patients were then matched for sex, age (within 6 years), and social class with normal controls. Each control was obtained among medical personnel of the clinic or clinic patients seen for refraction who had a 
Table $1 \quad$ 100-hue colour vision test in long-standing diabetes

\begin{tabular}{|c|c|c|c|c|c|c|c|c|c|c|}
\hline & \multirow[b]{2}{*}{ No. } & \multicolumn{6}{|c|}{ Diabetics } & \multicolumn{3}{|c|}{ Controls } \\
\hline & & $\begin{array}{l}\text { Age } \\
\text { (years) }\end{array}$ & $\begin{array}{l}\text { Duration } \\
\text { diabetes } \\
\text { (years) }\end{array}$ & $\begin{array}{l}\text { OD score } \\
O S\end{array}$ & Type* & $\begin{array}{l}\text { Severity } \\
\text { of } \\
\text { retinopathy }\end{array}$ & $\begin{array}{l}\text { Peripheral } \ddagger \\
\text { haemorrhages }\end{array}$ & Age & $\begin{array}{l}O D \text { score } \\
O S\end{array}$ & Type* \\
\hline \multirow[t]{14}{*}{ Females } & \multirow[t]{2}{*}{1} & \multirow[t]{2}{*}{36} & \multirow[t]{2}{*}{26} & 86 & YB & \multirow[t]{2}{*}{$\mathrm{m}$} & + & \multirow[t]{2}{*}{35} & 20 & YB \\
\hline & & & & 81 & YB & & + & & 35 & YB \\
\hline & \multirow[t]{2}{*}{2} & \multirow[t]{2}{*}{37} & \multirow[t]{2}{*}{30} & 60 & YB & $\mathrm{m}$ & ++ & \multirow[t]{2}{*}{36} & 86 & YB \\
\hline & & & & 24 & YB & & ++ & & 72 & Mi \\
\hline & \multirow[t]{2}{*}{3} & \multirow[t]{2}{*}{37} & \multirow[t]{2}{*}{34} & 142 & YB & Mo & + & \multirow[t]{2}{*}{38} & 50 & YB \\
\hline & & & & 191 & YB & & + & & 37 & Mi \\
\hline & \multirow[t]{2}{*}{4} & \multirow[t]{2}{*}{40} & \multirow[t]{2}{*}{32} & 105 & YB & Mo & + & \multirow[t]{2}{*}{42} & 66 & YB \\
\hline & & & & 53 & YB & & + & & 117 & YB \\
\hline & \multirow[t]{2}{*}{5} & \multirow[t]{2}{*}{44} & \multirow[t]{2}{*}{$35 \cdot 5$} & 42 & $\mathrm{Mi}$ & $\mathrm{m}$ & + & \multirow[t]{2}{*}{46} & 59 & YB \\
\hline & & & & 28 & YB & & + & & 60 & YB \\
\hline & \multirow[t]{2}{*}{6} & \multirow[t]{2}{*}{46} & \multirow[t]{2}{*}{26} & 127 & YB & Mo & ++ & \multirow[t]{2}{*}{52} & 86 & YB \\
\hline & & & & 119 & YB & & ++ & & 72 & $\mathrm{Mi}$ \\
\hline & \multirow[t]{2}{*}{7} & \multirow[t]{2}{*}{50} & 41 & 117 & YB & $\mathrm{m}$ & + & 53 & 99 & YB \\
\hline & & & & 102 & YB & & + & & 104 & YB \\
\hline Males & 8 & 40 & 27 & 159 & YB & Mo & ++ & 40 & 55 & YB \\
\hline & & & & 213 & Mi & & ++ & & 72 & YB \\
\hline & 9 & 49 & 34 & 375 & $\mathrm{Mi}$ & Mo & ++ & 46 & 139 & YB \\
\hline & & & & 310 & YB & & ++ & & 116 & YB \\
\hline & 10 & 54 & 29 & 121 & YB & $\mathrm{m}$ & + & 56 & 102 & YB \\
\hline & & & & - & - & & - & & 69 & YB \\
\hline & 11 & 55 & 42 & 63 & YB & $\mathrm{m}$ & + & 59 & 156 & $\mathrm{Mi}$ \\
\hline & & & & 86 & YB & & + & & 160 & YB \\
\hline & 12 & 56 & 37 & 46 & YB & $\mathrm{m}$ & + & 60 & 121 & YB \\
\hline & & & & 61 & YB & & + & & 89 & YB \\
\hline
\end{tabular}

${ }^{*} \mathrm{Y}-\mathrm{B}=$ yellow-blue; Mi: yellow blue and red green (mixed). $†$ m: mild; Mo: moderate. $\ddagger+: \leq 10 ;++:>10$.

normal ocular examination, no eye or systemic condition, and who was not receiving any medication. He or she was given the modified 100-hue colour vision test in the same manner as the experimental group. Social class was defined by the occupation of the head of the household. ${ }^{12}$

\section{Results}

Among the diabetics 7 women and 5 men (total of 23 eyes) were included in the final analysis. The mean age of the women was $41 \cdot 4$ years and of the men $50 \cdot 6$ years. The mean duration of diabetes was 32.8 years. All patients except one were middle class. All patients had 20/20 best corrected visual acuity, normal intraocular pressure, no lens changes by slit-lamp biomicroscopy, and minimal background diabetic retinopathy.

In a comparison of left and right eyes for 100-hue colour vision the scores revealed no significant differences $(t=0 \cdot 22)$. Therefore for all subsequent analyses the mean of the scores for the 2 eyes was taken as the measure of colour vision. In one subject (no. 10) only the right eye was measured because of significant lens changes in the other eye. This single value was included as the measure for that patient. Total score differences between cases and controls ranged from 215 units higher than the controls to a case 83.5 units lower than the control. The average difference between cases and controls was not significantly different $(t=1 \cdot 02)$ (Table 1$)$.

Comparing the colour pattern between left and right eyes and between cases and controls did not reveal any significant differences.

Means of 100 -hue scores were significantly higher in the group with moderate retinopathy $(159 \cdot 4)$ than

Table 2 Diabetic control

\begin{tabular}{llll}
\hline $\begin{array}{l}\text { Diabetic } \\
n o .\end{array}$ & \multicolumn{2}{l}{ Blood glucose $(\mathrm{mg} / \mathrm{dl})$} & $H b A_{1} \mathrm{C}(\%)$ \\
\cline { 2 - 3 } & Fasting & Postprandial & \\
\hline 1 & $205 \cdot 6$ & $146 \cdot 6$ & $12 \cdot 1$ \\
2 & $231 \cdot 4$ & $196 \cdot 4$ & $11 \cdot 2$ \\
3 & $148 \cdot 2$ & $241 \cdot 2$ & $10 \cdot 4$ \\
4 & $175 \cdot 0$ & $299 \cdot 2$ & $11 \cdot 7$ \\
5 & $212 \cdot 5$ & 265 & $12 \cdot 6$ \\
6 & $65 \cdot 4$ & 170 & $9 \cdot 1$ \\
7 & $144 \cdot 6$ & $204 \cdot 4$ & $9 \cdot 1$ \\
8 & 125 & $190 \cdot 4$ & $9 \cdot 4$ \\
9 & $92 \cdot 4$ & $205 \cdot 6$ & $10 \cdot 7$ \\
10 & $162 \cdot 2$ & $256 \cdot 0$ & $10 \cdot 5$ \\
11 & $99 \cdot 4$ & $193 \cdot 4$ & $10 \cdot 7$ \\
12 & - & $112 \cdot 2$ & 6.9 \\
\hline
\end{tabular}

SI conversion: blood glucose $\mathrm{mg} / \mathrm{dl} \times 0.0555=\mathrm{mmol} / \mathrm{l}$. 
in the group with mild retinopathy $(67 \cdot 6)(\mathrm{p}<0 \cdot 016)$. Means of 100 -hue scores were also significantly higher in the group with more than 10 retinal peripheral haemorrhages $(170 \cdot 1)$ than in the group with fewer peripheral haemorrhages $(72.9)(p<0.025)$.

When the logarithm of 100 -hue scores in diabetics was related to levels of 10 randomly chosen fasting and postprandial glucose and levels of haemoglobin $A_{1} C$, only fasting blood glucose levels were inversely related to the 100 -hue score $(\mathrm{p}<0.04)($ Table 2$)$.

\section{Discussion}

In this study the original 100-hue test procedure has been modified: Taylor pointed out, starting the 100hue test with box II, as was done here, makes the test easier to perform. ${ }^{13} \mathrm{Chip} 85$ has been omitted so that there is an equal number of 21 chips per box. ${ }^{14}$ In order to ensure that the protan and deutan confusion axes clearly fall in boxes I and III and the tritan axis in boxes I and IV, caps have been rearranged as follows: box I, 10-30; box II, 31-51; box III, 52-72; box IV, 73-9. ${ }^{10}$

Selection of patients and controls was strict: patients with any type of lens changes were excluded. Social class was also taken into account, as this might influence the understanding and the performance of the test.

In this group of diabetics the study does not confirm previous findings that loss of colour vision discrimination in diabetics precedes or is associated with minimal degrees of diabetic retinopathy,,$^{1-3}$ though we could not use the Lanthony desaturated DI5 test nor the Stiles increment threshold method which may have been more sensitive.$^{415}$ Extensive proliferative diabetic retinopathy may in fact coexist with a normal 100-hue score (personal observation).

All our patients had had diabetes for more than 25 years. Therefore duration of the disease does not appear to affect significantly colour vision, as was reported to be the case by Kinnear and Lakowski in a group of middle-aged diabetics. ${ }^{12}$ However, as shown by these authors, ${ }^{12}$ our study confirms that higher 100 -hue scores are found in patients with more marked diabetic retinal vascular lesions.

Among the usual measures of diabetic control only fasting blood glucose was inversely related to 100 -hue scores. The significance of this finding is not clear, as all patients were tested after lunch in order to avoid the deleterious effects of hypoglycaemia on colour vision scores. ${ }^{2}$ Unlike Muntoni's findings, the degree of colour vision loss was not related to current $\mathrm{HbA}_{1} \mathrm{C}$ levels. ${ }^{5}$ Our group of patients, although selected, had a wide range of haemoglobin $A_{1} C$ levels $(6.9 \%$ to $12.6 \%$ ), and 4 reported having been considered as brittle all their life. Lakowski also did not find any correlation between colour discrimination and quality of the diabetic control. ${ }^{2}$

This study shows that there is a positive correlation between colour vision scores as assessed by the 100hue test and diabetic retinal vascular lesions, though scores were not significantly different from normal subjects' scores. Overall, variability precludes a statement that colour vision as assessed by the 100 hue test is always worse in diabetes. Further studies using more sensitive methods of colour vision testing are in process in order to identify if loss of colour discrimination does indeed precede clinical diabetic retinopathy and could therefore serve as an early indication of neuronal damage in diabetes.

Thanks are due to J. Parker for his suggestions for analysing the data, to Mrs Chipman for the statistical analysis, and to JoAnn Bast for secretarial help.

\section{References}

1 Kinnear PR, Aspinall PA, Lakowski R. The diabetic eye and colour vision. Trans Ophthalmol Soc UK 1972; 92: 69-78.

2 Lakowski R, Aspinall PA, Kinnear PR. Association between colour vision losses and diabetes mellitus. Ophthalmic Res 1972; 4: $145-159$.

3 Saracco JB, Gastaud P, Estachy G et al. Intérêt du panel DI5 désaturé dans le dépistage de la rétinopathie diabétique. Bull Soc Ophtalmol Fr 1980; 10: 971-3.

4 Saracco JB, Gastaud P, Leid J, et al. Les doubles seuils colorés chez le diabétique: étude préliminaire. Bull Soc Ophtalmol Fr 1982; 12: 161-7.

5 Muntoni S, Serra A. Moscia C, Songini M. Dyschromatopsia in diabetes mellitus and its relation to metabolic control. Diabetes Care 1982; 5: 375-8.

6 Verriest, G. Further studies on acquired deficiency in colour discrimination. J Opt Soc Am 1963; 53: 185-95.

7 Lakowski R. Effects of age on the 100 hue scores of red-green deficient subjects. Color Vision Deficiencies II International Symposium, Edinburgh, 1973. Mod Probl Ophthalmol 1974; 13: 124-9.

8 Pinckers A. Color vision and age. Ophthalmologica 1980; 181: 23-30.

9 Saracco JB, Gastaud P, Trani JC, et al. Rôle de la saturation dans les tests utilisés pour l'examen de la vision des couleurs chez le diabétique. Bull Soc Ophtalmol Fr 1981; 11: 561-7.

10 Parker JA. Farnsworth 100 Hue scoring for acquired color vision deficiencies by weighted functions. In: Colenbrander A, Greenfield R, eds. Computers in ophthalmology. New York: Institute of Electrical and Electronics Ingenious, 1979: 97-9.

11 Roy MS, McCulloch JC. Peripheral retinal haemorrhages in longduration insulin-dependent diabetes with minimal background retinopathy. BrJ Ophthalmol 1982; 66: 286-9.

12 Goldthorpe JH, Hope K. The social grading of occupation: a new approach and scale. New York: Oxford University Press, 1974: 134-43.

13 Taylor WOG. Problems in performance and interpretation of Farnsworth's 100 hue test. Mod Probl Ophthalmol 1974; 13: 73-8.

14 Lakowski R. The Farnsworth 100 hue test. Ophthalmic Optician 1968; 8: 862-72.

15 Stiles WS. Colour vision: the approach through increment threshold sensitivity. Proc Natl Acad Sci USA 1949; 45: 100-14. 